\title{
IMPACTOS DA EXPANSÃO URBANA EM UM MUNICÍPIO METROPOLITANO: ANÁLISE DA RETIRADA DA COBERTURA VEGETAL DE APARECIDA DE GOIÂNIA, ENTRE 1985 E 2010
}

\author{
IMPACTS OF URBAN SPRAWL IN A METROPOLITAN MUNICIPALITY: \\ ANALYSIS OF THE VEGETATION COVER REMOVAL OF APARECIDA DE \\ GOIÂNIA, BETWEEN 1985 AND 2010 \\ LES IMPACTS DE L'ETALEMENT URBAIN DANS UNE MUNICIPALITE \\ METROPOLITAINE: ANALYSE DE LA SUPRESSION DU COUVERT VEGETAL \\ D'APARECIDA DE GOIANIA, ENTRE 1985 ET 2010 \\ Rubia Nara Silva Martins - Universidade Federal de Goiás - Goiânia - Goiás - Brasil \\ rubianara00@hotmail.com
}

\section{Resumo}

0 objetivo desse trabalho foi evidenciar 0 crescimento urbano de Aparecida de Goiânia, entre os anos de 1985 e 2010, e estabelecer sua relação com a degradação ambiental, especialmente no que se refere à retirada da cobertura vegetal. A metodologia utilizada compreendeu o levantamento bibliográfico acerca do tema, principalmente quanto à periodização desse município. Além disso, foram elaborados materiais cartográficos a partir dos quais foi realizada a análise quantificada das áreas urbanizadas. Com esse estudo, pretendeu-se cooperar com a discussão da expansão urbana de Aparecida de Goiânia por outro viés: a degradação ambiental do ambiente Cerrado desse município.

Palavras-chave: Aparecida de Goiânia, expansão urbana, cobertura vegetal.

\section{Abstract}

The goal of this paper was to highlight the urban sprawl of Aparecida de Goiânia, between 1985 and 2010, and to establish its relation with the environmental degradation, with special regard to the vegetation cover removal. In addition, the methodology used comprised the bibliographic survey about the theme, mainly concerning the periodization of this municipality. Besides, cartographic materials were elaborated from the quantified analysis done in the urbanized areas. To sum up, this study intended to cooperate with the discussion surrounding the urban sprawl of Aparecida de Goiânia through a different perspective, in other words, the degradation of the Brazilian Cerrado environment of this municipality.

Keywords: Aparecida de Goiânia, urban strawl, vegetation cover.

\section{Résumé}

Tout d'abord, l'objectif de cette étude était de mettre en évidence l'étalement urbain d'Aparecida de Goiânia, entre les années 1985 et 2010, et aussi, d'établir sa relation avec la dégradation de l'environnement, avec une attention particulière à la supression du couvert végétal. De plus, la méthodologie utilisée dans ce travail comporte l'étude bibliographique sur le thème cible, surtout en ce qui concerne la périodisation de cette municipalité. Par ailleurs, les matériels cartographiques ont été élaborés à partir de l'analyse quantifiée fait dans les zones urbanisées. Pour conclure, cette étude a eu le but de coopérer avec la discussion sur l'étalement urbain d'Aparecida de Goiânia, à travers un point de vue différent, en autres mots, la dégradation de l'environment Cerrado de cette municipalité.

Mots-clés: Aparecida de Goiânia, étalement urbain, le courvert végétal. 


\section{Introdução}

As transformações no espaço aparecidense vêm sendo objeto de estudo recente. As principais motivações evidenciadas são os processos ligados à intensa urbanização, sua relação com a capital goiana, e o processo de metropolização da região do entorno de Goiânia. Além disso, temas como a precarização, segregação, redes, crescimento desordenado sempre são discutidos sobre esse recorte espacial. A pergunta que permeia esse trabalho gira em torno da explosão e expansão demográfica urbana por que tem passado esse município nas últimas décadas, acentuadas pela falta de planejamento urbano ${ }^{1}$ e, consequentemente, ambiental.

Nesse sentido, destacou-se a necessidade de um trabalho que evidenciasse tanto a questão urbana, nesse caso a desordem urbana, como as possíveis consequências para esse ambiente. O principal objetivo é demonstrar o crescimento urbano de Aparecida de Goiânia, ${ }^{2}$ principalmente entre os anos de 1985 e 2010, e como esse processo de expansão urbana influenciou na retirada da cobertura vegetal natural desse município.

A metodologia utilizada foi a realização de um levantamento bibliográfico acerca do tema, bem como a coleta de dados demográficos disponibilizados pelo IBGE. Além disso, foram utilizadas quatro imagens orbitais, obtidas por meio do satélite LandSat 5 referente aos anos de 1985, 1995, 2005 e 2010, ou seja, um intervalo temporal de 25 anos. Por meio dessas imagens, foram elaborados mapas temáticos de uso e cobertura do solo para os referidos anos. Também utilizaram-se dados da prefeitura de Aparecida de Goiânia para elaboração de um mapa de loteamentos por década de aprovação, e foi adquirido o mapa urbano digital do município.

\section{0 incremento demográfico de Aparecida de Goiânia}

O crescimento urbano de Aparecida de Goiânia se confunde com o seu próprio enredo histórico. O município iniciou sua trajetória como um vilarejo, para atender às necessidades das fazendas estabelecidas na região. Cita-se, além do fator econômico, o simbólico e político traduzido por meio de doações de terras para a igreja católica, que construiu a Igreja de Nossa Senhora de Aparecida, fator que impulsionou o crescimento desse até então vilarejo. Portanto, o município surge diante de um quadro já conhecido e comum entre várias cidades goianas: seu marco histórico, 
a igreja, onde atualmente localiza-se o bairro central dessa cidade, data do início da década de 1920. Como argumentam Chaul e Duarte (2004):

As cidades goianas nasceram arraiais, viraram vilas, depois, com o tempo, ganharam formas de abrigo de pessoas e sedes administrativas e/ou políticas. Umas sim, outras não. Geralmente começavam com uma ou outra casa ou casebre, uma pequena praça, uma tímida igreja. (Chaul e Duarte, 2004, p. 7)

A discussão que se desenvolverá a partir de agora foi baseada na periodização realizada por alguns autores, em que explicitam processos históricos, sociais e econômicos. É importante salientar que a problematização por eles realizada segue objetivos diferentes. Entretanto não se contradizem, se complementam. Segundo Santos (2008), Aparecida de Goiânia divide-se em quatro períodos, como se verifica no Quadro 1.

Quadro 1 - Periodização para o processo de estruturação do espaço intraurbano de Aparecida de Goiânia

\begin{tabular}{|l|l|}
\hline Período & Tema \\
\hline De 1922 a 1963 & De núcleo isolado à constituição de espaços segregados. \\
\hline De 1963 a 1980 & $\begin{array}{l}\text { Da estruturação do espaço metropolitano à produção de periferia } \\
\text { expandida e segregada. }\end{array}$ \\
\hline De 1980 a 1990 & Consolidando a segregação: o crescimento demográfico. \\
\hline De 1990 até os dias atuais & $\begin{array}{l}\text { A constituição de uma região geral multifuncional integrada à } \\
\text { cidade. }\end{array}$ \\
\hline
\end{tabular}

Fonte: Santos (2008)

Concomitantemente, Pinto (2009) delimitou o espaço-tempo do município também em quatro períodos (Quadro 2).

Apesar da coincidência quanto à quantidade de períodos definidos por esses dois autores, pode-se destacar que há diferenças tanto em seu período temporal, quanto nos processos ali delineados por eles. O interesse em utilizar essas periodizações se relaciona com o trabalho em questão, primeiramente porque ambos citam esse crescimento urbano ligado a uma periferização, e em segundo lugar, há um desordenamento, gerado pela falta de um instrumento efetivo de reforma urbana, que, nas palavras de Souza (2008, p. 113), coíbe a especulação imobiliária, promove a segregação residencial e a disparidade socioeconômica intraurbana. Esse último 
ponto abordado é de suma importância para se tentar compreender como se deu o crescimento urbano desordenado em contraposição à degradação ambiental, principalmente quanto à retirada de cobertura vegetal original em decorrência da ocupação humana. Vale ressaltar que os dois últimos períodos do Quadro 1 e o último período do Quadro 2 correspondem ao recorte temporal adotado nesse estudo, que salienta o crescimento urbano de 1985 a 2010.

Quadro 2 - Síntese das fases espaço-temporais de Aparecida de Goiânia

\begin{tabular}{|l|l|l|}
\hline Período & Tema & Características norteadoras \\
\hline $\begin{array}{l}\text { De 1922 a } \\
1935\end{array}$ & $\begin{array}{l}\text { Origem do povoado no } \\
\text { contexto rural goiano }\end{array}$ & $\begin{array}{l}\text { Origem religiosa; povoado rural; incorporação } \\
\text { ao município de Goiânia (pouca proximidade } \\
\text { com a capital). }\end{array}$ \\
\hline $\begin{array}{l}\text { De 1935 a } \\
1963\end{array}$ & $\begin{array}{l}\text { Entrelaçamento } \\
\text { descontínuo com a capital } \\
\text { e emancipação política }\end{array}$ & $\begin{array}{l}\text { Consolidação do distrito de Aparecida; novos } \\
\text { loteamentos descontínuos do núcleo original; } \\
\text { incremento populacional e conurbação } \\
\text { (dependência da capital). }\end{array}$ \\
\hline $\begin{array}{l}\text { De 1963 a } \\
1990\end{array}$ & $\begin{array}{l}\text { Crescimento urbano e } \\
\text { periferização }\end{array}$ & $\begin{array}{l}\text { Zona receptora de migração; intenso } \\
\text { parcelamento do solo; desordenamento urbano } \\
\text { e falta de infraestrutura básica (estereótipo de } \\
\text { "cidade dormitório”). }\end{array}$ \\
\hline $\begin{array}{c}\text { De 1990 } \\
\text { até os } \\
\text { dias } \\
\text { atuais }\end{array}$ & $\begin{array}{l}\text { Novas funcionalidades no } \\
\text { espaço fragmentado }\end{array}$ & $\begin{array}{l}\text { Contenção ao parcelamento do solo; } \\
\text { implantação descontínua de infraestrutura } \\
\text { urbana; novas centralidades; relação de } \\
\text { complementaridade e interdependência com } \\
\text { Goiânia (periferia dinâmica). }\end{array}$ \\
\hline
\end{tabular}

Fonte: Pinto (2009)

No Quadro 2, é possível vislumbrar o processo de formação do espaço aparecidense de forma sucinta, porém muito completa em todos os seus aspectos. Já no Quadro 1, esse processo foi montado na tentativa de demonstrar que o município foi se constituindo como um território segregado, principalmente por seu vínculo com Goiânia a partir do seu crescimento em direção à capital, ainda na década de 1950/1960. Conclui-se que esse espaço nos propicia uma profunda discussão sobre metropolização, redes, crescimento urbano, periferização, segregação urbana, questão ambiental, entre outras questões. E, ainda, para tentar representar como esse espaço foi sendo tomado pelos loteamentos ao longo do tempo e melhor ilustrar esse processo, observa-se a Figura 1, na qual se representa por 
décadas como ocorreu a expansão de bairros/loteamentos no município de Aparecida de Goiânia.

Percebe-se claramente que a expansão de Aparecida de Goiânia deu-se de forma espraiada, e que não segue o modelo de crescimento das cidades em torno do seu centro histórico. Nota-se que na década de 1950 o parcelamento se dá às margens do limite norte-sul, entre Aparecida de Goiânia e Goiânia, o que reflete uma ligação do município com a capital. E, ainda, que há um vertiginoso aumento de loteamentos na década de 1970, e que esse aumento continua, porém em menor quantidade na década de 1980, diminuindo bastante nas décadas seguintes.

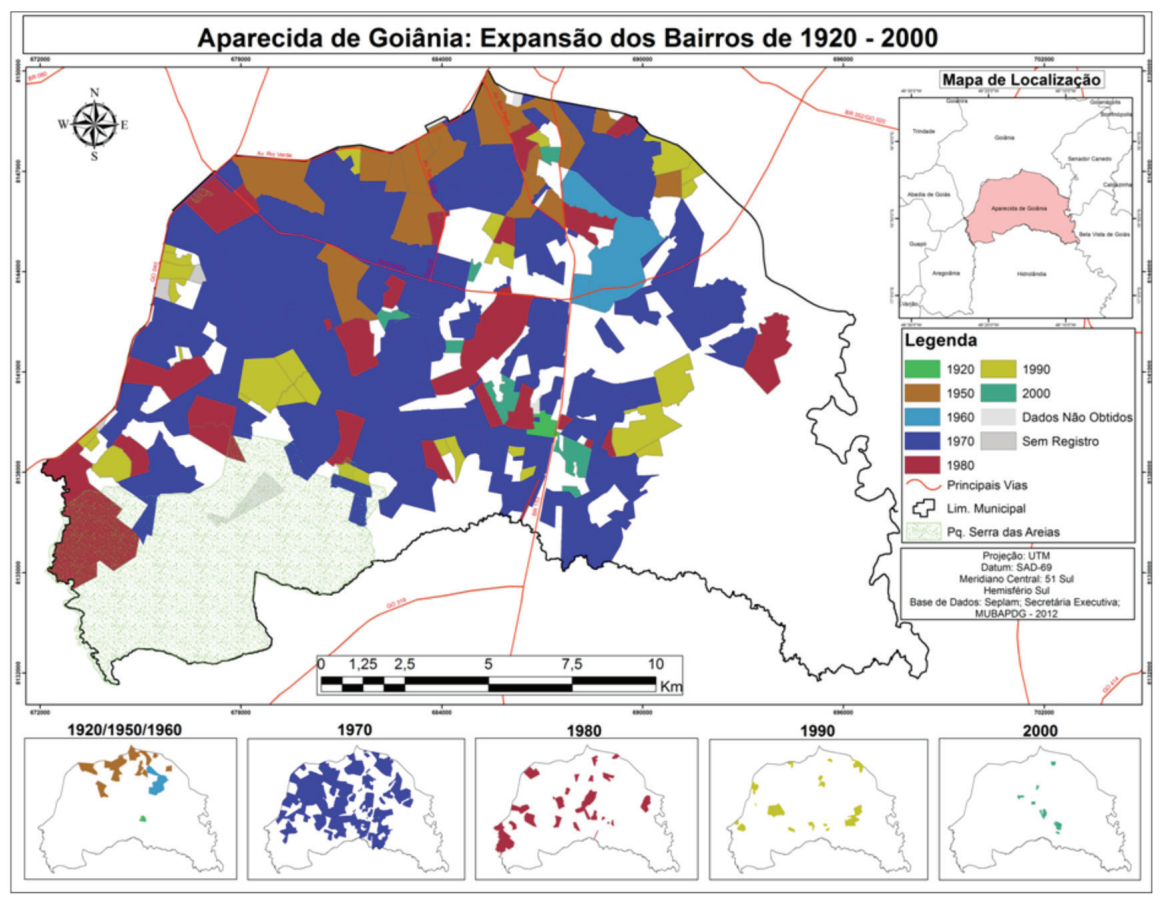

Figura 1 - Aparecida de Goiânia - criação de bairros/loteamentos de 1920 até os dias atuais Fonte: Secretaria Executiva (2012); Pinto (2006) e Santos (2008)

Observou-se que a expansão urbana nas décadas destacadas relaciona-se com os processos periodizados dos autores supracitados. Pode-se relacionar, por exemplo, o crescimento dos loteamentos na década de 
1970 à especulação imobiliária. Segundo o Plano Diretor de Aparecida de Goiânia (2001), esse motivo justifica-se, pois em Goiânia, no início dessa década, foi aprovada lei municipal que controlava com vigor a aprovação de loteamentos, os quais deviam contar com infraestrutura básica. Devido à proximidade e ao baixo valor dos lotes em Aparecida de Goiânia, houve um grande aumento desses loteamentos/bairros e, consequentemente, o aumento da precariedade das condições de moradia, pois não havia a infraestrutura necessária para receber a população, além de existir um grande número de lotes vagos em razão da especulação imobiliária, fato que ocorre até os dias atuais.

Já as décadas de 1980 e 1990 são marcadas pelo grande aumento populacional, como podem comprovar os dados dos censos das últimas décadas. Deve-se salientar que o incremento populacional nas últimas três décadas deu-se de forma desordenada e sem a devida atenção à população que se estabelecia no município. Esses fatos, consequentemente, podem ser traduzidos em uma urbanização desatenta aos aspectos socioambientais, assim como nas décadas anteriores.

O raciocínio realizado até aqui sobre a urbanização desordenada de Aparecida de Goiânia teve por objetivo ressaltar como se sequenciou processualmente esse desordenamento urbano e, de forma bem sucinta, destacar os impactos negativos gerados. Porém, a partir daqui, o objetivo será desvelar os impactos negativos ocorridos pela degradação ambiental no município em decorrência desse crescimento urbano desordenado.

\section{0 mapeamento da expansão urbana e a degradação do Cerrado em Aparecida de Goiânia}

Observa-se que a cobertura vegetal natural já não era expressiva na década de 1980, tendo por referência a imagem de 1985 (Figura 2). Surge então uma questão: foi realmente a expansão urbana que suprimiu a cobertura vegetal natural? A indagação é pertinente, pois o município, antes de ser parcelado, era formado por boa parte de fazendas, principalmente para o uso da agropecuária. Historicamente, segundo Chaveiro (2004), Aparecida de Goiânia estava inserida na lógica do Estado de Goiás do início do século: o motivador principal da economia era a agropecuária. Além disso, deve-se refletir sobre qual tipo de vegetação estaria concentrada no território aparecidense. 
De acordo com Barbosa, Teixeira Neto e Gomes (2004), parte desse território estava inserido no chamado Mato Grosso Goiano (denominou-se assim o território cuja vegetação era constituída de cerrado stricto). Ou seja, havia, sim, uma considerável cobertura vegetal. E, como dito anteriormente, em contraposição ao domínio de Aparecida de Goiânia por fazendas.

Deve-se destacar que a urbanização não foi o principal motivo da retirada da cobertura vegetal, porém foi um dos principais motivadores. Destaca-se também a lógica econômica do território antes do século XX, que muito contribuiu para essa degradação ambiental.

O trabalho demonstrará, de maneira técnica, como ocorreu a degradação do cerrado, com a retirada da cobertura vegetal natural em decorrência da expansão urbana, especificamente entre os anos de 1985 e 2010. Esse período foi escolhido por dois motivos básicos: a partir da década de 1980 é que teve início a grande pressão populacional que o município vem sofrendo; o segundo motivo condiz com parte do procedimento aplicado, já que foram utilizadas imagens orbitais dos anos de 1985, 1995, 2005 e 2010.

O mapa a seguir (Figura 2) demonstra a ocupação urbana de Aparecida de Goiânia até 1985. Nota-se que o município já revela o fenômeno da conurbação com Goiânia, ou seja, um vetor de crescimento voltado para a parte norte de Aparecida de Goiânia indo ao encontro do sul da capital.

O principal motivo desse crescimento voltado para Goiânia se deve ao fato de que a capital exerce o papel de centralizadora/polarizadora dentre os seus municípios vizinhos. Além disso, Goiânia, desde a sua construção, sofreu um intenso crescimento horizontal, influenciando o crescimento dos municípios circunvizinhos. Conforme dito anteriormente, o vertiginoso crescimento de Aparecida de Goiânia deu-se na década de 1970, aliado ao aumento populacional nas décadas posteriores. Conforme afirma Arrais (2004):

Imaginem quantos bairros não surgiram desde então! Foram muitos. Mais de 230, segundo dados da Prefeitura Municipal. A cobertura vegetal original foi praticamente destruída à medida que iam surgindo bairros, muitos dos quais irregulares e na sua maioria sem infraestrutura urbana, fator que barateava o custo dos lotes, atraindo milhares de pessoas. (Arrais, 2004, p. 123) 


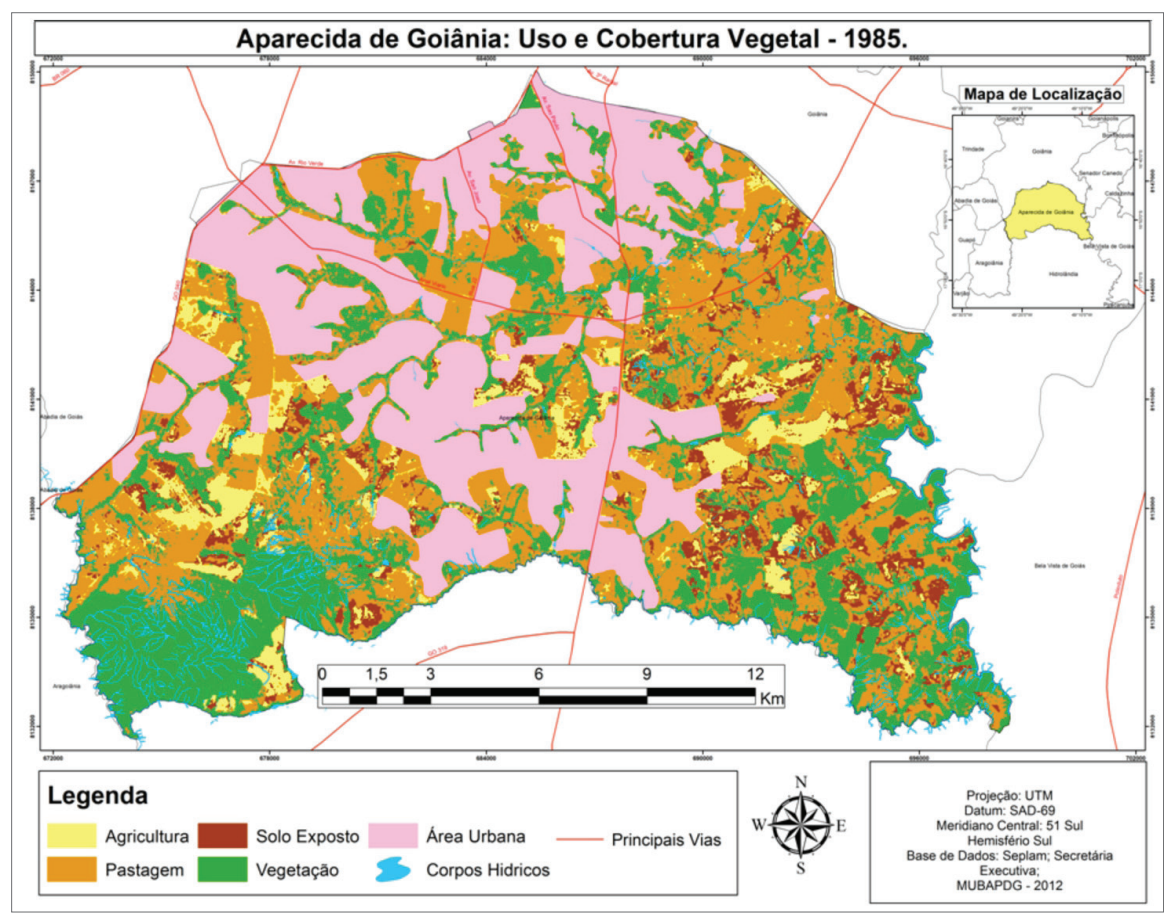

Figura 2 - Mapa de uso e cobertura vegetal de Aparecida de Goiânia referente ao ano de 1985

Assim, destaca-se mais uma vez a preocupação advinda de uma falta de planejamento, em que a cidade fica à mercê do capital imobiliário, sem se medirem as consequências que poderiam ocorrer. Observa-se a falta de comprometimento com as políticas sociais e ambientais, haja vista o discurso de Freud de Melo, revelando seus planos para Aparecida de Goiânia, que se transformaria em cidade-dormitório:

[...] Então decidi lotear quase todo o território municipal, no sentido de Goiânia a Aparecida, mas pelo seu lado direito, em sua grande parte constituída de cerrado - impróprio para exploração agropastoril, porém adequado a edificações de qualquer natureza -, certo de que no futuro ali se assentaria o maior setor residencial, e muito habitado, abrigaria uma farta mão de obra migrante, tão necessária à grandiosidade construtiva do próprio goianiense e aparecidense. (Melo, 2002, p. 70) 
Os dados populacionais - revelando a dinâmica vivida pelo município nas décadas referidas - podem ser comparados na Tabela 1. Observa-se um grande aumento da população em relação às décadas de 1970/1980 e 1980/1990. Da população referida na década de 1970, aproximadamente 6.600 pessoas viviam na zona rural, segundo dados do IBGE.

Tabela 1 - Aparecida de Goiânia: população total e crescimento populacional

\begin{tabular}{|l|c|c|c|c|c|}
\hline Ano & $\mathbf{1 9 7 0}$ & $\mathbf{1 9 8 0}$ & $\mathbf{1 9 9 1}$ & $\mathbf{2 0 0 0}$ & $\mathbf{2 0 1 0}$ \\
\hline População Total & 7.470 & 42.627 & 178.483 & 336.392 & 455.657 \\
\hline Crescimento Populacional (\%) & - & $471 \%$ & $319 \%$ & $88 \%$ & $35 \%$ \\
\hline
\end{tabular}

Fonte: IBGE - Censos Demográficos 1970, 1980, 1991, 2000 e 2010

Quantificando a área mapeada, também pode se observar como a dinâmica da ocupação do solo acompanha a dinâmica populacional. Na década de 1980, a mancha urbana cobre quase 30\% do município. Em contrapartida, a vegetação natural corresponde aproximadamente a $26 \%$ (Tabela 2). O que o mapa ainda revela é uma mancha urbana ainda bem espraiada, contrapondo-se a grandes "ilhas urbanas".

Tabela 2 - Quantificação das classes de uso e cobertura vegetal de 1985

\begin{tabular}{|l|c|c|c|}
\hline CLASSES & Área $\left(\mathbf{K m}^{\mathbf{2}} \mathbf{)}\right.$ & Área (ha) & Área Relativa (\%) \\
\hline Agricultura & 22,407 & 2240,6701 & 7,694560637 \\
\hline Pastagem & 92,802 & 9280,1628 & 31,86849121 \\
\hline Solo Exposto & 19,347 & 1934,6780 & 6,643770176 \\
\hline Vegetação & 74,428 & 7442,8000 & 25,55890575 \\
\hline Área Urbana & 82,219 & 8221,8716 & 28,23427223 \\
\hline Área Total & 291,202 & 29120,1825 & 100 \\
\hline
\end{tabular}

Nota-se também que tanto o mapa (Figura 2) quanto a tabela (Tabela 2) demonstram uma grande quantidade de solo exposto e pastagem, que são considerados como área propícia para a expansão urbana.

Com relação à década de 1990, representada pela imagem de 1995, pode-se observar que a área urbana continua se expandindo em relação à década de 1980, como é demonstrado na Figura 3. Nota-se que a cobertura vegetal diminuiu cerca de 827 hectares em relação à década anterior. 


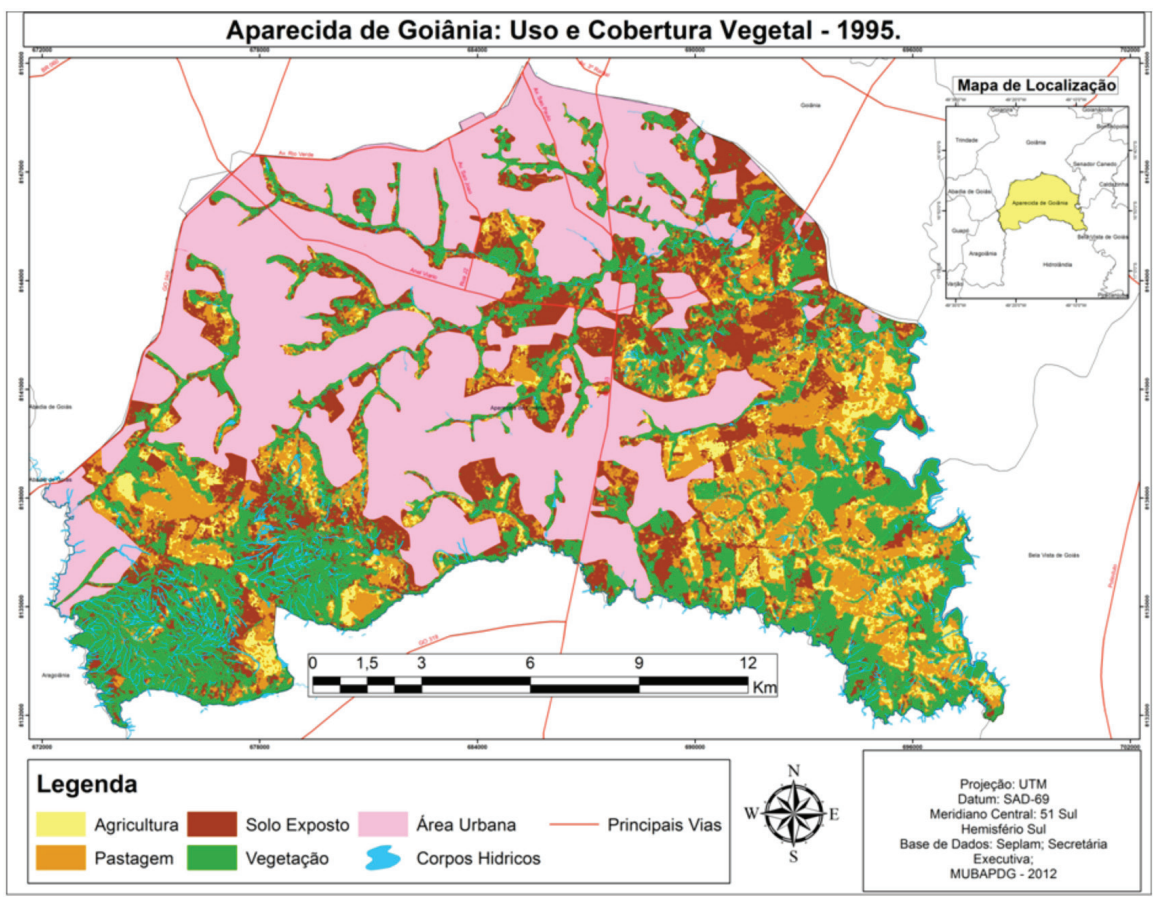

Figura 3 - Mapa de uso e cobertura vegetal de Aparecida de Goiânia referente ao ano de 1995

Como o procedimento realizado consiste no processamento de imagens orbitais, a técnica adotada não representa 100\% a realidade, uma vez que são frequentes as confusões espectrais. É possível visualizar que a vegetação foi alterada. Comparando-se as Figuras 2 e 3, percebe-se que houve uma detecção maior de pequenas áreas verdes no mapeamento pela imagem de 1985 (Figura 2) que não foram detectadas na imagem de 1995 (Figura 3). Porém, o solo exposto, que alcançava quase 7\% na década anterior, alcança pouco mais de 16\% em 1995, como ilustra a Tabela 3. As classes de agricultura e principalmente a pastagem sofreram uma pequena oscilação, assim como ocorreu com a vegetação.

O crescimento da área urbana acompanhou o crescimento populacional, que alcançou aproximadamente 180.000 habitantes já na década de 1990. Segundo Pinto (2009), é a partir de 1990 que Aparecida de Goiânia tem sua reestruturação interna, principalmente por meio das novas centralidades. Cita como exemplo a região do Buriti Shopping. Entretanto, 
o município vive uma contradição em seu território, pois há, sim, um crescimento da área urbana, bem como da população, porém esses fenômenos não vêm acompanhados de infraestrutura básica, o que resulta em algumas consequências negativas para a população aparecidense.

Tabela 3 - Quantificação das classes de uso e cobertura vegetal de 1995

\begin{tabular}{|l|c|c|c|}
\hline CLASSES & Área $\left(\mathbf{K m}^{2}\right)$ & Área (ha) & Área Relativa (\%) \\
\hline Agricultura & 17,8148 & 1781,4841 & 6,117695519 \\
\hline Pastagem & 45,5839 & 4558,3874 & 15,65370478 \\
\hline Solo Exposto & 47,1717 & 4717,1661 & 16,19895789 \\
\hline Vegetação & 66,1598 & 6615,9761 & 22,71955576 \\
\hline Área Urbana & 114,4717 & 11447,1688 & 39,31008605 \\
\hline Área Total & 291,2019 & 29120,1825 & 100 \\
\hline
\end{tabular}

Santos (2008) e Pinto (2009) concordam que a década de 1990 é marcada por intensas mudanças internas em Aparecida de Goiânia. Concordam também sobre a efetivação de novos centros e sobre a crescente indústria no município, fatores que refletiram diretamente na expansão urbana, já que a demanda por serviços aumentou bastante. Fatores que envolvem uma gama de serviços ligados à infraestrutura básica, como o aumento do número de comércios, hospitais, unidades de ensino superior e básico, agências bancárias, entre outros.

As mudanças ocorridas foram um motivador a mais para a expansão da população. A década de 1990 é marcada pela diminuição de loteamentos, como já dito anteriormente, porém há um incremento em infraestrutura, o que justificou uma expansão populacional efetiva. Constatou-se uma supressão da cobertura vegetal, causando danos, comprometendo esse incremento urbano.

A década de 2000 vem para consolidar os processos ocorridos na década de 1990. Em relação ao mapeamento, o ano de referência foi o de 2005, como ilustra a Figura 4. Esse mapa reflete como a expansão urbana ainda continua crescente. Em contrapartida, houve uma diminuição da cobertura vegetal, principalmente nas bordas sul do município e nas matas ciliares. A diminuição da cobertura vegetal nas bordas justifica-se pelo aumento da agricultura nessa região, como evidencia a imagem. A diminuição das matas ciliares reflete a pressão urbana, pois ocorreu principalmente na área urbanizada. Há ainda uma diminuição da quanti- 
dade de solo exposto, que foi claramente substituído pela pastagem e área urbana (Tabela 4).

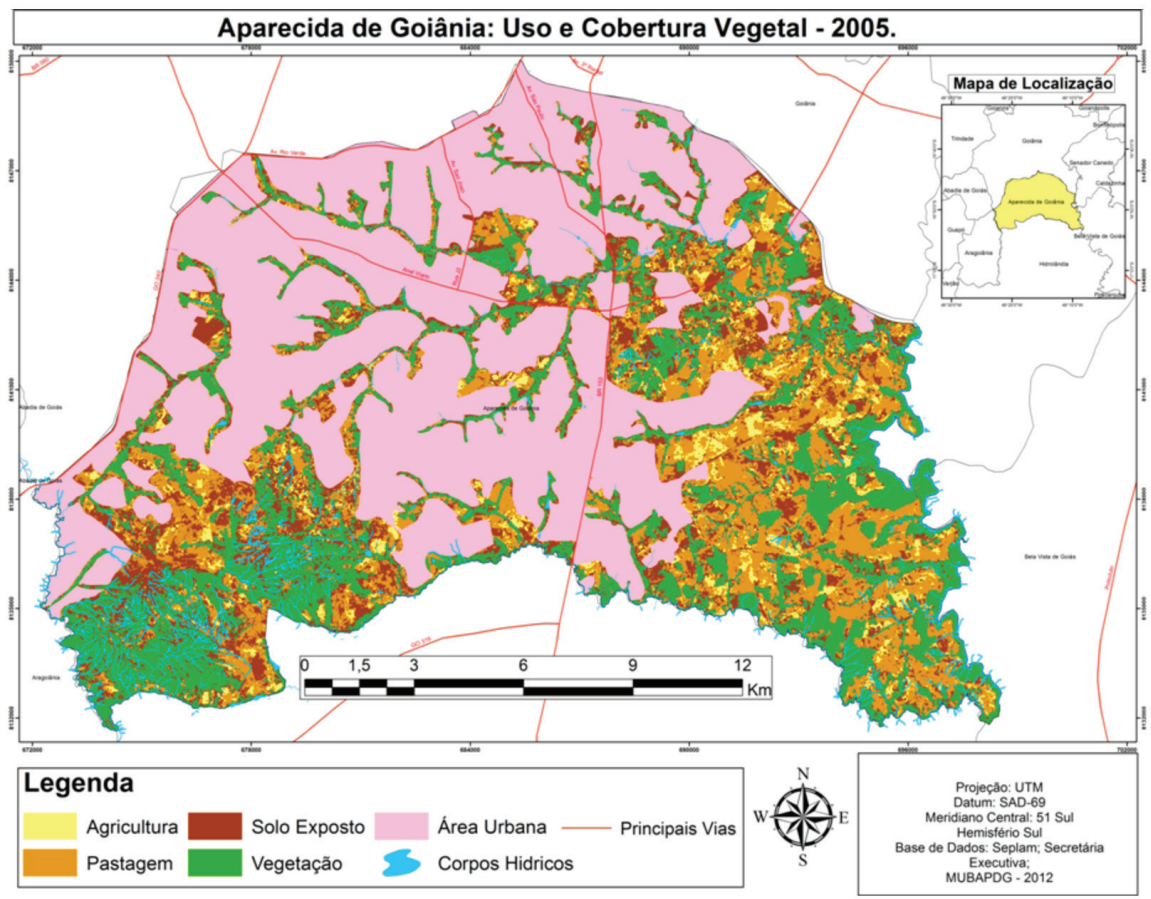

Figura 4 - Mapa de uso e cobertura vegetal de Aparecida de Goiânia referente ao ano de 2005

Tabela 4 - Quantificação das classes de uso e cobertura vegetal de 2005

\begin{tabular}{|l|c|c|c|}
\hline CLASSES & Área $\left.\mathbf{( K m}^{2}\right)$ & Área (ha) & Área Relativa (\%) \\
\hline Agricultura & 15,1003 & 1510,0269 & 5,185499456 \\
\hline Pastagem & 46,4627 & 4646,2702 & 15,95549827 \\
\hline Solo Exposto & 41,0327 & 4103,2691 & 14,09080837 \\
\hline Vegetação & 59,1934 & 5919,3418 & 20,3272827 \\
\hline Área Urbana & 129,4127 & 12941,2744 & 44,44091119 \\
\hline Área Total & 291,2018 & 29120,1824 & 100 \\
\hline
\end{tabular}


A retirada da mata ciliar é um dos grandes problemas ambientais enfrentados em ambientes urbanos, o que contraria leis regidas pelas esferas governamentais, pois a destruição da mata ciliar é proibida por leis municipais e estaduais. Entretanto, torna-se um problema comum nas cidades, onde não há um monitoramento e fiscalização a contento. O mapa revelou também que grande parte do Parque Municipal da Serra das Areias $^{3}$ estava sendo utilizada como área de pastagens. Como o parque constituiu-se Área de Proteção Ambiental (APA), pela Lei Municipal $\mathrm{n}^{0} 2.018$, de 23/11/1999, a legislação não estava sendo praticada. Segundo Pinto (2006), grande parte da Serra das Areias foi invadida por loteamentos, bem como por chácaras, inclusive sendo várias sem registro.

A mancha urbana avançou nas direções oeste, sul e centro do município, deixando para a agricultura e área de pastagens parte da direção leste. A partir desse momento o crescimento urbano já não demonstra uma expansão espraiada como nas décadas iniciais do seu crescimento. Constatou-se que, de 1985 até 2005, mais de 44\% da área territorial do município pertencia à expansão urbana, ou seja, vinte anos depois o município aumentou sua área urbana em aproximadamente 4720 hectares, enquanto a área de cobertura vegetal natural foi suprimida em pouco mais de 1500 hectares.

O ano em questão é o de 2010, o último da análise proposta. Esse ano marca o fim de um ciclo de 25 anos de expansão urbana e suas consequências, como pode ser verificado na Figura 5.

O mapeamento demonstra uma pressão urbana ainda mais ressaltada que em 2005. Novamente esse contingente populacional ocorre principalmente às margens das drenagens do município, porém, em vez de substituir as áreas verdes, foram substituídas as áreas de pastagens, que foram muito degradadas, como relatado anteriormente em relação ao uso e cobertura vegetal do ano de 2005.

Mais uma vez, a questão da Serra das Areias é retomada, pois mais uma vez sofreu muita pressão por conta do avanço da mancha urbana, pelo aumento da área de pastagens e solo exposto. Em dados quantitativos, isso pode ser observado com mais clareza na Tabela 5. 


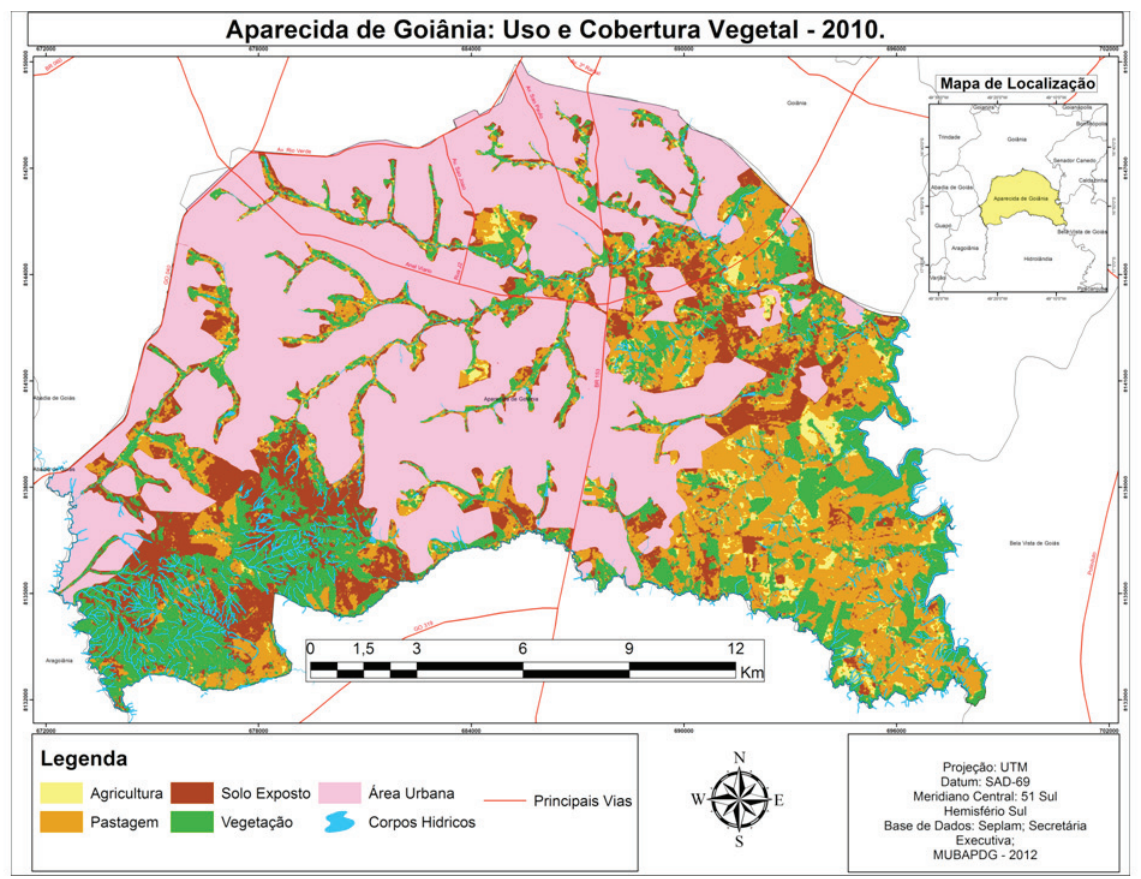

Figura 5 - Mapa de uso e cobertura vegetal de Aparecida de Goiânia referente ao ano de 2010

Tabela 5 - Quantificação das classes de uso e cobertura vegetal de 2010

\begin{tabular}{|l|c|c|c|}
\hline CLASSES & Área $\left(\mathbf{K m}^{2}\right)$ & Área (ha) & Área Relativa (\%) \\
\hline Agricultura & 9,5849 & 958,4925 & 3,278264467 \\
\hline Pastagem & 55,5357 & 5553,5658 & 18,99447041 \\
\hline Solo Exposto & 37,3466 & 3734,6625 & 12,77340341 \\
\hline Vegetação & 53,0470 & 5304,6957 & 18,14327751 \\
\hline Área Urbana & 136,8639 & 13686,3863 & 46,81058421 \\
\hline Área Total & 292,3781 & 29237,8028 & 100 \\
\hline
\end{tabular}

A pastagem alcançou quase $19 \%$, enquanto a cobertura vegetal natural ultrapassou pouco mais de $18 \%$. Essa queda aconteceu principalmente nas margens dos córregos. Além disso, os dados revelaram que houve uma diminuição na área de agricultura, principalmente em relação 
ao ano de 2005. A explicação mais sensata é que essa área foi substituída por área de pastagem. Há áreas que aparecem como solo exposto na parte oeste e leste do município; algumas se relacionam com a extração mineral que é realizada nessa porção de Aparecida de Goiânia, e que culmina sempre em degradação. Observa-se que as áreas de agricultura e pastagens oscilaram em relação a 2005 e 2010. Analisando a tabela a seguir (Tabela 6), verifica-se que na realidade as áreas oscilaram, porém o número de pessoas que habitam essas áreas rurais não variou nos últimos 10 anos.

Tabela 6 - Tipos de domicílios de Aparecida de Goiânia entre os anos de 2000 e 2010

\begin{tabular}{|l|c|c|}
\hline \multicolumn{1}{|c|}{ Tipos de Domicílios } & 2000 & 2010 \\
\hline Domicílios Particulares Permanentes Urbanos & 90.704 & 136.230 \\
\hline Domicílios Particulares Permanentes Rurais & 239 & 272 \\
\hline
\end{tabular}

Fonte: IBGE, 2012

Verifica-se ainda que o número de domicílios permanentes na área urbana aumentou pouco mais de 50\% em apenas 10 anos, o que demonstra que Aparecida de Goiânia ainda se encontra em notável crescimento. Claro que não da mesma forma e proporção que na década de 1970, quando os loteamentos foram liberados em grande número, mas na forma de preenchimento desses lotes vagos com construções de casas, prédios de apartamentos, enfim, uma tentativa de sanar um problema proeminente na cidade.

Fica evidente que houve uma intensa urbanização nesses vinte e cinco anos em Aparecida de Goiânia (conforme ilustra a Figura 6) e ocorreram muitas transformações, porém essa expansão demográfica foi realizada alheia ao planejamento urbano, causando consequências negativas ao município. A questão que foi destacada com maior ênfase neste estudo foi a perda da cobertura vegetal natural, como demonstra a Figura 7.

É notório que há supressão da cobertura vegetal natural. A retirada dessa vegetação é visível em duas áreas já destacadas anteriormente: a mata ciliar, ou seja, a vegetação que envolve o leito do rio; e grande parte da vegetação que foi retirada do Parque Municipal da Serra das Areias, unidade de conservação do município. São duas áreas que deveriam ser preservadas, já que ambas são protegidas por legislação ambiental. 

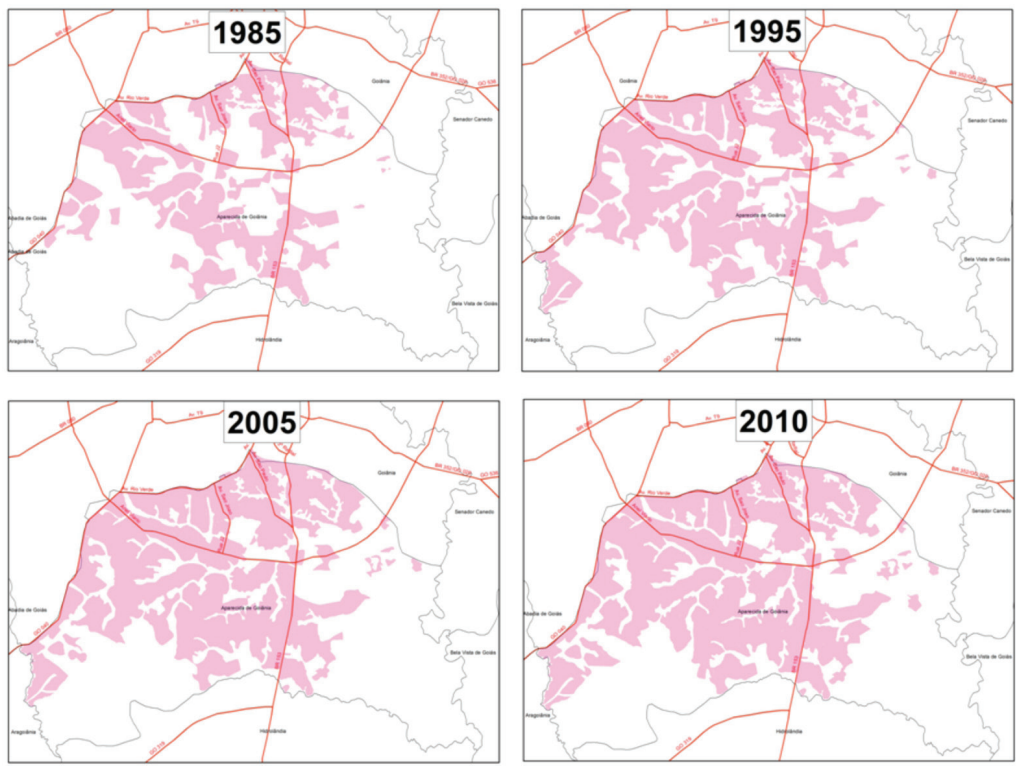

Figura 6 - Expansão urbana de Aparecida de Goiânia nos anos de 1985, 1995, 2005 e 2010
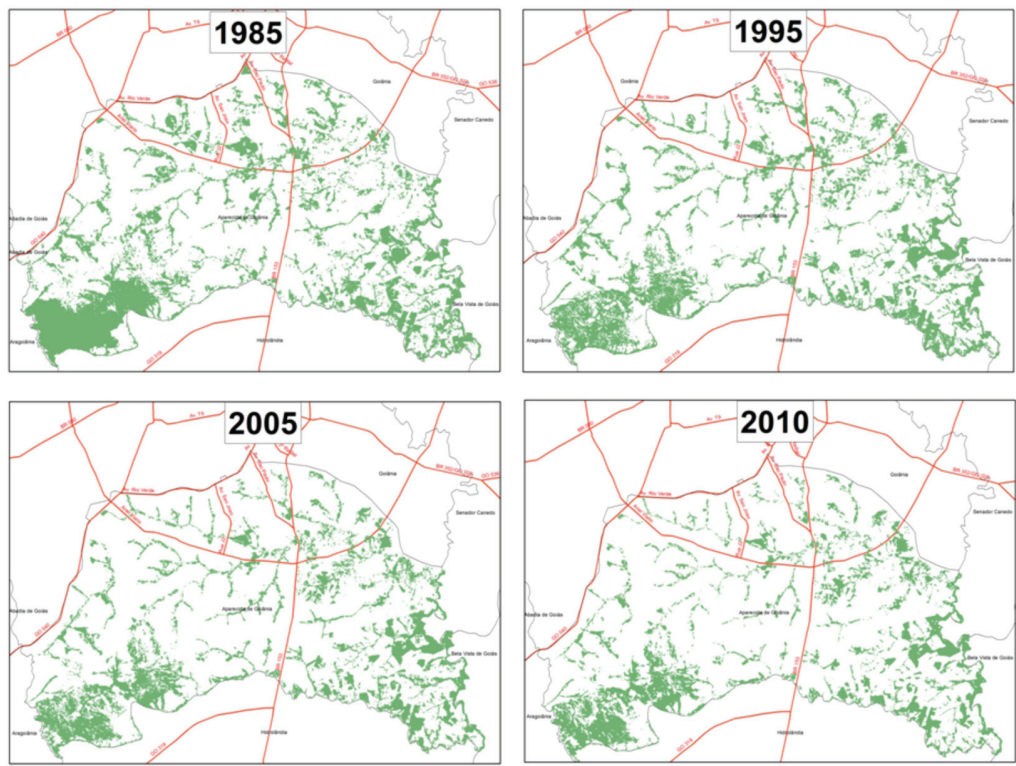

Figura 7 - Cobertura vegetal natural nos anos de 1985, 1995, 2005 e 2010 
Concomitantemente, notou-se que a região sudeste do município, área que o crescimento urbano ainda não alcançou, foi a que menos perdeu a cobertura vegetal natural (essa área teve parte de sua vegetação retirada por outras práticas, tais como a agricultura e a pecuária). Desse modo, vislumbra-se uma relação impactante entre expansão urbana e cobertura vegetal natural.

\section{Considerações Finais}

Este trabalho teve por objetivo geral evidenciar a expansão urbana de Aparecida de Goiânia e a sua relação com a degradação ambiental, na forma da retirada de sua cobertura vegetal, entre os anos de 1985 e 2010. Na primeira parte do trabalho fez-se um breve histórico do município e foi realizada uma análise por meio de duas periodizações realizadas por Santos (2008) e Pinto (2009). Os dois autores evidenciaram que Aparecida de Goiânia passou por quatro períodos distintos, dando margem à discussão sobre os processos ocorridos no município. $\mathrm{O}$ foco neste trabalho, para utilizar as periodizações, foi a expansão urbana e os principais motivos que levaram a ela.

Em um segundo momento, foi realizada a análise por meio do mapeamento do uso e cobertura vegetal nos anos 1985, 1995, 2005 e 2010 . O principal objetivo aqui era desvelar até que ponto houve uma supressão da cobertura vegetal e a relação impactante entre crescimento urbano e cobertura vegetal natural. Concluiu-se que houve realmente uma grande retirada da cobertura vegetal natural durante esses anos, mas também houve grande devastação dessa cobertura nos anos de 1970, já que essa década foi marcada por uma intensa aprovação de loteamentos. Evidenciou-se, ainda, que antes mesmo da grande expansão urbana iniciada nos anos 1960/1970, já havia ocorrido uma expressiva retirada da cobertura vegetal natural para usos do solo para a pecuária e a agricultura.

Foi demonstrado como se deu o crescimento nesses quatro anos 1985, 1995, 2005 e 2010 -, e evidenciou-se que no ano de 1985 a mancha urbana se apresentou espraiada em direção ao norte do município de Aparecida de Goiânia, na direção da capital. Dez anos após, notou-se um crescimento em torno dos espaços vizinhos, ainda na direção norte do município, e um leve aumento das áreas verdes, principalmente na zona 
urbana. Fato ligado ao crescimento condicionado e direcionado à capital, Goiânia, um centro polarizador dos seus demais municípios vizinhos.

A década de 1990 foi marcada por um aumento da demanda populacional e, consequentemente, de infraestrutura e serviços no município. Nos anos 2000, essa demanda é atendida com uma maior infraestrutura e aumenta o crescimento populacional. Nessa década, a dinâmica foi determinada pelo preenchimento dos espaços já loteados. Porém, ficou evidente outro vetor de crescimento direcionado para o sul do município. E, ainda, uma clara diminuição da cobertura vegetal natural, principalmente na região da Serra das Areias e matas ciliares.

Por fim, a última imagem revelou que muitos dos espaços vazios dos loteamentos continuavam a ser preenchidos, principalmente nessa última década. Conclui-se que esse preenchimento tem a ver com a estrutura econômica iniciada na década de 1990, com a formação de polos industriais; contribuiu também a acessibilidade a alguns terminais de ônibus que foram sendo construídos nesse período, favorecendo uma maior locomoção dentro do município e para a Região Metropolitana de Goiânia. Quanto à cobertura vegetal natural, praticamente se manteve, perdendo só parte de sua área para a área de pastagens.

Pode-se destacar que seria interessante a realização de estudos utilizando-se imagens a partir da década de 1970, para que a investigação se torne mais completa. Além disso, é necessário um constante monitoramento por parte dos órgãos responsáveis pela manutenção das áreas verdes, principalmente na área da Serra das Areias, área de recarga do lençol freático, o que ressalta ainda mais sua importância.

Convém destacar que grande parte dessa área é ocupada por uma parcela da população que vive às margens da reforma urbana, devido à falta de políticas públicas de moradia. E ainda, avaliou-se a necessidade de instrumentos de planejamento que realmente lidem com a questão socioambiental de forma conjunta e efetiva, principalmente em regiões metropolitanas, a fim de se evitarem transtornos ambientais incalculáveis.

\section{Notas}

1. Segundo Souza (2010, p. 58), o planejamento urbano deve ser sempre associado à gestão, buscando o entrosamento entre a evolução espacial em sua forma e função sem ignorar os fatores políticos, históricos e sociais. 
2. O município de Aparecida de Goiânia obteve esse nome oficialmente somente em 1963, pela Lei Estadual no 4.927, que elevava o então distrito de Goiânia à categoria de Município.

3. Pela Lei Municipal $n^{0} 2.018$, de 23 de novembro de 1999, foi criado o Parque Municipal da Serra das Areias, constituindo-se Área de Proteção Ambiental (APA).

\section{Referências}

APARECIDA DE GOIÂNIA. Lei Municipal n. 2.018, de 23 de novembro de 1999. Desapropria a área denominada Serra das Areias, considerada como área de utilidade pública, para fins de criação do Parque Municipal da Serra das Areias e dá outras providências.

APARECIDA DE GOIÂNIA, Prefeitura Municipal de Aparecida de Goiânia. Plano Diretor - Decenal 2001/2011. Aparecida de Goiânia, 2001.

ARRAIS, Tadeu Pereira Alencar. Geografia contemporânea de Goiás. Goiânia: Ed. Vieira, 2004.

BARBOSA, Altair Sales; GOMES, Horieste; TEIXEIRA NETO, Antônio. Geografia Goiás Tocantins. Goiânia: Ed. UFG, 2004.

CHAUL, Nasr Fayad; DUARTE, Luis Sérgio. As cidades dos sonhos (Apresentação). In: CHAUL, Nasr Fayad; DUARTE, Luis Sérgio (Orgs.). As cidades dos sonhos: desenvolvimento urbano em Goiás. Goiânia: UFG, 2004. p. 7-14.

CHAVEIRO, Eguimar Felício. A urbanização do sertão goiano e a criação de Goiânia. In: NETO, Antônio Teixeira et al. O espaço goiano: abordagens geográficas. Associação dos Geógrafos Brasileiros, 2004.

. Goiânia: Travessias sociais e paisagens cindidas. Goiânia: UCG, 2007.

MELO, Freud de. Aparecida de Goiânia: do zero ao infinito. Goiânia: Asa, 2002.

PINTO, José Vandério Cirqueira. Fragmentação da metrópole: constituição da região metropolitana de Goiânia e suas implicações no espaço intraurbano de Aparecida de Goiânia. Dissertação (Mestrado em Geografia) - Instituto de Estudos Socioambientais, UFG, Goiânia, 2009.

. Impactos socioambientais na Serra das Areias decorrentes do crescimento urbano desordenado em Aparecida de Goiânia. 2006. Disponível em: <http://www. ufg.br/this2/uploads/files/214/PINTO__Jos_Vand_rio_Cirqueira_impactos_s_ cio_ambientais.pdf>. Acesso em: 20 jun. 2012.

SANTOS, Lucas Maia. A produção do espaço intraurbano de Aparecida de Goiânia e a dinâmica metropolitana de Goiânia: de 1960 a 2000. Dissertação (Mestrado em Geografia) - Instituto de Estudos Socioambientais, UFG, Goiânia, 2008.

SOUZA, Marcelo Lopes de. ABC do desenvolvimento urbano. 4. ed. Rio de Janeiro: Bertrand Brasil, 2008.

- Mudar a cidade: uma introdução crítica ao planejamento e à gestão urbanos. 7. ed. Rio de Janeiro: Bertrand Brasil, 2010. 
Rubia Nara Silva Martins - Licenciada e Bacharel em Geografia pela Universidade Federal de Goiás - Especialista em Educação Integral e Integrada pela mesma instituição - Mestranda na Universidade Federal de Goiás Professora efetiva na Rede Estadual de Educação.

Recebido para publicação em 11 de fevereiro de 2013 Aceito para publicação em 29 de maio de 2013 